\title{
Tipicidad y legalidad en el derecho administrativo-sancionatorio
}

\author{
Fernando Londoño Martínez*
}

\begin{abstract}
RESUMEN
En el texto se defiende la conveniencia de distinguir entre tipicidad penal (estricta) y tipicidad en el derecho administrativo-sancionatorio (más laxa). Las razones para una tal distinción se ponen en evidencia tomando nota del tipo de razonamiento práctico comprometido en el diseño normativo de una y otra rama. Di allí la atención del artículo al análisis de la law \& economics y a su consecuencialismo subyacente. En fin, se esboza un estándar adecuado de tipicidad para el derecho administrativo-sancionatorio, estándar que el autor describe bajo la noción de marco suficiente de legalidad.
\end{abstract}

Tipicidad - administrativo sancionatorio - consecuencialismo

\section{Legal description and legality in administrative penalties}

\begin{abstract}
This paper supports the distinction between the requirement of a strict description of criminal offences and the weaker requirement in this aspect affecting the description of administrative offences. The reasons for such a distinction become apparent once different kind of practical reasoning involved in the regulation of criminal and administrative law are considered. This explains why the article engages in the analysis of Law E Economics and its underlying consequentialist reasoning. It is suggested that an adequate legal standard to assess the description of the administrative offences may respond to the idea of 'sufficient framework of legality'.
\end{abstract}

Description of the offence - administrative penalties - consequentialism

* Doctor en Derecho. Profesor asistente de Derecho Penal de la Universidad Diego Portales. Correo electrónico: fernando.londono@udp.cl.

Artículo recibido el 3 de marzo de 2014 y aceptado para su publicación por el Comité Editorial el 29 de octubre de 2014.

Este trabajo corresponde a mi intervención en las X Jornadas de Derecho Administrativo, cuya versión resumida fue leída el 22 de noviembre en la Facultad de Derecho de la Universidad de los Andes. Un agradecimiento especial debo a los colegas Matías Guiloff, Héctor Hernández, Raúl Letelier, Pablo Soto y Alex van Weezel, por las valiosas referencias y observaciones formuladas a una versión preliminar del presente trabajo. 


\section{EL PROBLEMA: ¿TIPICIDAD (PENAL) EN EL ADMINISTRATIVO SANCIONATORIO?}

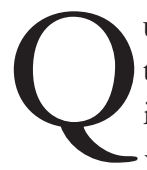
ue las disciplinas del derecho dialoguen e intercambien modelos de imputación no es nuevo. De reciente, en la década de los noventa, se advertía el ingreso de lo dispositivo en el procedimiento penal y de lo inquisitivo en su versión civil. Una suerte de influencia recíproca. Presenciamos un fenómeno análogo entre derecho penal y derecho administrativo ${ }^{1}$. Mientras en el marco del primero se suele hablar de administrativización del derecho penal (piénsese en la dulcificación de las penas, en la tutela de contextos cada vez más genéricos y la gestión de riesgos generales por vía penal, en las dinámicas de justicia negociada y en la administración de los términos procesales por agentes dotados con crecientes poderes discrecionales) ${ }^{2}$, en el campo del segundo se asiste a una suerte de criminalización del derecho sancionatorioadministrativo $^{3}$ (por de pronto aparecen poderes nuevos de persecución y se invoca con cada vez más fuerza un arsenal de garantías frente al persecutor administrativo) ${ }^{4}$.

${ }^{1}$ Reconociendo la comunicabilidad entre ambas ramas, en una suerte de coordinación en el marco de un "proyecto de sistema represivo modulado", Pedrazzi, Cesare, "Diritto Penale", en Diritto Penale, Scritti di Parte Generale, t. I. Giuffré, Milán, 2003, pp. 147 ss, pp. 150-151 (se trata de la reedición en opera omnia del original publicado como voz en Digesto delle Discipline Penalistiche, Utet, 4a ed., Turín, 1990, 64 ss.).

${ }^{2}$ Al respecto, ampliamente, Silva Sánchez, Jesús María, La expansión del derecho penal. Aspectos de política criminal en las sociedades postindustriales, Civitas, 2da. Ed., Madrid, 2001, especialmente pp. 74-79 (con alusión al "gerencialismo") y 120-147 (con referencia a la "administrativización del derecho penal").

${ }^{3}$ El término no es preciso; quizás habría que decir, menos sintéticamente: "asimilación de contenidos del derecho penal por el sancionatorio-administrativo”. Por sancionatorio-administrativo entiendo especialmente aquel que se desprende de la actividad regulatoria de la Administración.

${ }^{4} \mathrm{Cfr}$., especialmente representativo por lo que se refiere a la invocación de garantías para el sancionatorio administrativo, defendiendo - para dichos propósitos- una identidad completa entre administrativo sancionatorio y derecho penal (entre pena y sanción administrativa), el volumen de AA.VV., Sanciones administrativas y derechos fundamentales: regulación y nuevo intervencionismo. Conferencias Santo Tomás de Aquino, Andros, Santiago, 2005. De entre las varias contribuciones de ese volumen, considérense especialmente las intervenciones de Soto Kloss, Eduardo, "La potestad sancionadora de la Administración, ¿se adecua a la Constitución?", pp. 29-49 (aunque sosteniendo derechamente la ilegitimidad del sancionatorio-administrativo a la luz de su lectura de la CPR vigente; tesis ya expuesta en su "El Derecho Administrativo Penal”, en Boletín de Investigaciones, Facultad de Derecho de la PUC de Chile, 1979-1980, No 44-45, pp. 95-103); Aguerrea, Pedro, "El estatuto constitucional de las penas. Su aplicación a las sanciones administrativas conforme a los antecedentes de la Comisión de Estudio de la Nueva Constitución" (pp. 51-62); y Alcalde, Enrique, "Bienes jurídicos protegidos y potestad sancionadora de la Administración” (pp. 63-71). También en esta línea favorable a la equivalencia de naturaleza y garantías, cfr. Boettiger, Camila, "El derecho administrativo sancionador en la jurisprudencia del Tribunal Constitucional", en Actualidad Jurídica, No 20, 2009, pp. 577ss, pp. 585587; Alcalde, Enrique, "Aplicación de los principios de tipicidad, culpabilidad y proporcionalidad en la infracción administrativa”, en Actualidad Jurídica, No 24, 2011, pp. 69-84, pp. 69-70; y, en fin, acotado al subsector del derecho societario, Del Mismo Autor, La responsabilidad de los directores de sociedades anónimas. Responsabilidad civil y penal administrativa, Ediciones Universidad Católica de Chile, Santiago, 2013, cap. IV, pp. 317 ss. Para una posición discrepante de las anteriores, de reciente, cfr. Cordero Q., Eduardo y Aldunate L., Eduardo, "Las bases constitucionales de la potestad sancionadora de la Administración”, en Revista de Derecho de la Pontificia Universidad Católica de Valparaíso XXXIX, 2012 (2 ${ }^{\text {do }}$ Semestre), pp. 337-361, con amplias referencias bibliográficas ulteriores. La jurisprudencia constitucional, por su parte, ha transitado desde el mero reconocimiento de la adscripción de ambos tipos de sanciones al ius puniendi estatal (punto ya afirmado 
Ahora bien, ¿tiene sentido este intercambio de modelos?

Una respuesta cabal a la pregunta anterior supondría una toma de posición amplia, cual teoría general del derecho sancionatorio tout court. Por razones de competencia, contexto y espacio, aquí solo abordaré un extremo de la ecuación: la criminalización del sancionatorio-administrativo. En ese marco y por las mismas razones de obligada economía, me concentraré en una sola dimensión del problema; a saber, el principio de tipicidad. Pues bien, reformulando la pregunta de apertura, tocará preguntarse si es defendible la idea de tipicidad (en sentido fuerte=penal) en el administrativo-sancionatorio 5 .

Puedo ya aquí anticipar de manera muy general mi aproximación al problema. Mis sucesivas observaciones apuntarán a justificar la siguiente conclusión: en el plano de la tipicidad los parámetros de garantía deberían permanecer diferenciados entre una y otra rama ${ }^{6}$. Esta afirmación debería resultar aún más clara tratándose

para el principio de legalidad en STC Rol No 46 de 21 de diciembre de 1987 [caso Clodomiro Almeyda], y más tarde reiterado en STC Rol No 244 de 26 de agosto de 1996 [caso Ley de caza-SAG]), hacia una calibración más fina de aquello que distingue a ambos regímenes sancionatorios, afirmando así que las garantías y principios penales tienen rendimiento en el administrativo-sancionatorio "con matices". En esta línea, para materias de legalidad-tipicidad, los pronunciamientos vinculados a los casos Eléctricas, STC Rol No 480 de 27 de julio de 2006 (considerando $5^{\circ}$ ) y STC Rol No 479 de 8 de agosto de 2006 (de contenido equivalente al Rol No 480). Pertinentes también, en cuanto aluden a la doctrina del TC de vigencia de garantías "con matices", las más recientes STC No 1518 de 21 de octubre de 2010 (caso ISP-art.169 CSan; considerandos $6^{\circ}$ y $30^{\circ}$, en materia de convertibilidad de la sanción administrativa) y STC Rol No 2381 de 20 de agosto de 2013 (caso Pollos; considerandos $13^{\circ}, 16^{\circ}$ y $17^{\circ}$, en materia de derecho a no autoincriminarse). Por su parte, la Corte Suprema habría reconocido la vigencia de las garantías del derecho penal para el sancionatorio administrativo ya en sendos pronunciamientos de 1966 (31 de marzo y 12 de julio), para transitar desde entonces -aún con mayor énfasis que el TC- hacia un reconocimiento matizado de dichas garantías para el sancionatorioadministrativo, sin advertir condiciones de absoluta identidad o equivalencia entre ambas tipologías de sanción (al menos por lo que se refiere al principio de legalidad), destacando entre los más recientes el pronunciamiento de la Corte Suprema en recurso de queja de 25 de octubre de 2012, Rol No 6030-2012 (caso Megavisión-CNTV), en el que expresamente se pronuncia por una tipicidad diferenciada -más laxa-para el administrativo sancionatorio (cfr. su considerando $3^{\circ}$ especialmente; crítica, Veas, Constanza, "Principio de Tipicidad en el Derecho Administrativo Sancionatorio", en Henríquez, Ian (Coord.), Derecho corporativo. Jurisprudencia Comentada. Año 2013, Legal Publishing -Thomson Reuters, Santiago, 2013, pp. 77-82). Para un ágil panorama del estado jurisprudencial en el sancionatorio-administrativo, más allá del solo principio de legalidad, (hasta 2011, incluyendo STC, SCS y Contraloría), puede consultarse Cordero Vega, Luis, "En qué estamos con el Derecho Administrativo Sancionador", en El Mercurio Legal, 16 de agosto de 2011. En fin, para una acabada descripción (crítica) de la jurisprudencia constitucional en materia de tipicidad, tanto para el derecho penal como para el administrativo sancionatorio, cfr. el ensayo de Weezel, Alex Van, La Garantía de Tipicidad en la jurisprudencia del Tribunal Constitucional, Abeledo Perrot-Thomson Reuters, Santiago, 2011, deteniéndose además en el diálogo o discrepancia interna del TC, en torno al concreto fundamento constitucional de la garantía de tipicidad para el administrativo sancionatorio.

${ }^{5}$ Afirmando una tipicidad en sentido penal, entre otros ya citados en nota precedente, Alcalde, E., "Aplicación de los principios...", pp. 69-74 y "La responsabilidad de los directores...", pp. 337-344. En esta posición correspondería ubicar también a Weezel, Alex Van., La garantía de tipicidad, op. cit., pp. 168 y 201, crítico de la jurisprudencia constitucional en cuanto -a partir de los casos Eléctricas- legitimaría un "estándar inferior" de tipicidad, que se conformaría con la sola descripción legal de un deber de conducta.

${ }^{6}$ Como se ha indicado supra en nota $\mathrm{n}^{\circ} 4$, en nuestro medio, esta diferenciación se desprende de la jurisprudencia constitucional STC Rol No 480 de 27 de julio de 2006 y STC Rol No 479 de 8 de agosto de 2006 (casos Eléctricas). Por su parte, en esta línea se ubica el también ya aludido pronunciamiento de 
del sancionatorio-gubernativo ${ }^{7}$, en especial de aquel cuyo objeto es la regulación de sectores habitados por agentes económicos. Expresado lo anterior en términos todavía generales, mi posición es que -estando a la tradicional dicotomía rule/standard ${ }^{8}$ - el

la Corte Suprema en Rol No 6030-2012 (caso Megavisión-CNTV), en cuyo considerando $3^{\circ}$ puede leerse que "la naturaleza de las contravenciones administrativas, en las que confluyen componentes técnicos, dinámicos y sujetos a variabilidad en el tiempo, hace imposible su síntesis descriptiva en un precepto general como lo es una ley, de modo que el principio de tipicidad al traspasarse al ámbito sancionatorio de la Administración admite ciertos grados de atenuación”. En fin, y como se detalla infra en nota ${ }^{\circ} 39$, esta perspectiva habría también inspirado al legislador para la reforma en materia de libre competencia. Por lo que se refiere a la situación en derecho comparado y a la jurisprudencia internacional en materia de derechos humanos (contexto este último en el que la garantía de tipicidad splo se predica para el derecho penal, cobrando vigencia para el administrativo sancionatorio sólo allí donde se advierta un fraude de etiquetas), algo más se dirá en el curso de este trabajo, pero puede ya adelantarse un juicio que sintetiza el estado de la cuestión en un ordenamiento de ordinaria referencia en nuestro medio: así, Schmidt-Assmann, Eberhard, La teoría general del derecho administrativo como sistema, Marcial Pons, Madrid, 2003, pp. 205 ss., p. 207, en donde "los estrictos criterios por los que se rige la determinación de la ley penal (mandato de lex certa), establecidos en el artículo 103.2 [de la Constitución alemana], no son extrapolables a las leyes administrativas", agregando luego que "el Tribunal Constitucional Federal [alemán] ha advertido acertadamente del peligro que comporta una concepción exagerada según la cual toda norma debiera ofrecer en todos los sentidos certeza absoluta" [basándose en BVerfGE, 80,103 (108); y BVerfGE, 47, 327 (385 y 386)]. Es importante advertir en todo caso que este mismo autor ofrece criterios "moderadores", tendientes a instar por estándares superiores de determinación legal en el contexto administrativo tout court, según se retomará infra (cfr. nota $\left.n^{\circ} 14\right)$.

${ }^{7}$ Siguiendo la distinción que se desprende del art. 20 del Código Penal, entre sanciones administrativas gubernativas y disciplinarias. Al respecto, cfr., ampliamente, Hernández Basualto, Héctor, Comentario al artículo 20 del Código Penal, en Couso, Jaime y Hernández, Héctor (Dir.), Código Penal Comentado. Parte General. Doctrina y Jurisprudencia, Ed. Abeledo Perrot-Legal Publishing, Santiago, 2011, pp. 445-446. Igualmente, cfr. Cury Urzúa, Enrique, Derecho Penal. Parte General, Ediciones Universidad Católica de Chile, $7^{\text {a }}$ Ed., 2005, pp. 103-104. En este contexto debe advertirse que, si alguno lo tiene, el rendimiento de lo aquí expuesto parece más modesto tratándose del sancionatorio-disciplinario. Lo anterior no tanto en razón de un diverso carácter de las sanciones o una diversa cualidad de los destinatarios -aspectos ambos en los que no se advierten diferencias relevantes con el sancionatorio gubernativo (salvo por lo que se refiere a que en el primero solo intervienen personas naturales, nunca personas jurídicas)- sino en cuanto en el sancionatorio disciplinario el escenario de finalidades resulta sustancialmente más acotado, reduciéndose básicamente a los intereses de buen servicio y eficiencia del organismo de que se trate. De allí entonces que, en ese contexto, la necesidad de estándares flexibles para adecuar los outputs a mejoras de sistema aparezca como artificiosa.

${ }^{8}$ De acuerdo con los planteamientos más extendidos, la distinción entre una y otra categoría radica en el carácter ex ante (rule) o ex post (standard) predicado para la atribución de contenido de una determinada disposición legal. La distinción puede hallarse en Hart, Herbert L.A., The concept of law, Oxford University Press, $2^{a}$ ed., 1994, pp. 131 ss. (cap. VII.1) [= pp. 126 ss. de la versión original de 1961; la referencia para la traducción al castellano de la primera edición de 1961 puede hallarse en El Concepto de derecho (trad. Genaro R. Carrió), Abeledo Perrot, Buenos Aires, 1998, pp. 163 ss.]. En lo demás, se ha tenido especialmente a la vista Kaplow, Louis, "Rules versus standards: an economic analysis", en Duke Law Journal, vol. 42, 1992-1993, pp. 557 ss., pp. 559-560, para quien sería una regla aquella en la que el esfuerzo de asignación de contenido normativo ocurre en un momento anterior al de la acción del regulado (atribución de contenido ex ante), mientras que un estándar se caracterizaría por un esfuerzo de asignación de contenido en un momento posterior al de la acción del regulado (atribución de contenido expost). Así, estando al ejemplo que ofrece el propio Kaplow, sería una regla aquella que prohíba "manejar a más de 55 millas por hora en autopistas", mientras que sería un estándar aquel que prohíba "manejar a 
legislador penal debe procurar identificar las conductas prohibidas (tipicidad) con la medida estricta de las rules ${ }^{9}$, mientras que en el administrativo-sancionatorio el uso de standards para análogos propósitos debe considerarse adecuado o suficiente ${ }^{10}$. Por su parte, los aplicadores penales deberían sujetarse estrictamente al (idealmente apretado) espacio que ofrecen los tipos penales, buscando identificar la correcta subsunción del hecho en la regla, sin consideraciones de sistema que vayan más allá de la adecuada solución al caso concreto. Los aplicadores de sanciones administrativas, en cambio, no siempre atados por regulaciones estrictas, deberían poder moldear la solución del caso en función de variables de sistemas. Lo anterior, por cierto, sin perjuicio del respeto a la legalidad ${ }^{11}$.

Pues bien, ¿por qué puede tener sentido esta solución diferenciadora en el plano de la tipicidad? En lo sucesivo procuraré responder a esta pregunta. Una toma de posición directa se ofrece en la sección III. Con todo, dicha postura puede quedar parcialmente desprovista de fundamento sin una explicación relativa al tipo de razonamientos comprometidos en el diseño normativo que nos ocupa. Ese espacio será materia de la sección II, a la que de inmediato me encamino. Desde esta sección se captará el por qué de la atención al análisis de la law E economics y a su consecuencialismo subyacente.

una velocidad excesiva en autopistas". Como puede advertirse, y siguiendo siempre las explicaciones de Kaplow, en el primer caso quien dicta la regla deja solo variables fácticas a consideración del adjudicador, reservándose la determinación del tipo de conducta prohibida o permitida; en cambio, en el caso del estándar, quien dicta la norma entrega también al adjudicador la determinación del específico tipo de conducta prohibida o permitida (amén de la variable fáctica, por cierto). Como es evidente, los tipos penales se ajustan al modelo de reglas.

9 Se trata solo de una aspiración ideal, pues su precisa concreción parece relativizada por las limitaciones del lenguaje, amén del recurso -inevitable en un plano de regulación desde lo alto, en abstracto- a "conceptos necesitados de complementación valorativa" (wertausfüllungsbedürftigen Begriffe): cfr. en este sentido, Roxin, Claus, Derecho Penal. Parte General. Tomo I (trad. 2da ed. alemana), Ed. Civitas, Madrid, 1997, p. 170, §5, nm. 67 [= ID, Strafrecht AT, 4a ed., C.H. Beck, München, 2006, S. 173, §5, Rn. 69]. En este mismo sentido, desde el derecho administrativo y con aval en los pronunciamientos del Tribunal Constitucional federal [especialmente BVerfGE, 80, 103 (108); BVerfGE, 8, 274 (326); BVerfGE, 49,89 (144ss); y BVerfGE, 77, 214 (219)], cfr. Schmidt-Assmann, E. op. cit., no 6, pp. 207 ss., según el cual "para la Constitución [alemana] los límites estructurales a que se halla sometida toda programación normativa, ya solo por la necesidad de formular con los limitados medios del lenguaje un supuesto de hecho abstracto, son expresión de un estado de normalidad. Precisamente en este contexto se inscribe la utilización por el legislador de conceptos normativos indeterminados, de cláusulas generales y de habilitaciones discrecionales". (op. cit. p. 207). Aunque en sentido crítico, el punto es reconocido como un dato por Weezel, Alex Van, op. cit, $\mathrm{n}^{\circ} 4, \mathrm{p} .5$, con referencia a la situación del delito imprudente en nuestra legislación (art. $490 \mathrm{CP}$ ).

${ }^{10}$ Cabe todavía preguntarse por el margen de elasticidad razonable o suficiente de estos estándares para no defraudar expectativas impostergables de legalidad; algo al respecto se dirá infra en III.A.

${ }^{11} \mathrm{Cfr}$. lo dicho infra en III.A, especialmente en nota $\mathrm{n}^{\circ} 42$, en polémica con un reciente pronunciamiento de la Tercera Sala de la Corte Suprema (Rol 7397-2012, caso Essbio), en cuanto desdibuja por completo la base mínima de legalidad requerida para fundar el recurso a las sanciones administrativas. 


\section{Premisas para una toma de posición: RAZONAMiENTO CONSECUENCIALISTA Y RAZONAMIENTO NO CONSECUENCIALISTA}

II.A

A mi juicio, diversos factores explican la conveniencia de diferenciar entre tipicidad (penal) y legalidad administrativa-sancionatoria.

Para defender mi posición daré cuenta del tipo de razonamiento práctico que está en la base del modelo sancionatorio de la law E economics. Afirmaré que se trata de un razonamiento de tipo consecuencialista y lo contrastaré con un razonamiento no consecuencialista. La comparación de uno y otro - sobre todo a la luz del contenido comunicativo de las normas que emanan de una y otra rama del derecho- ofrecerá un escenario adecuado para advertir que el legislador penal y el legislador sancionatorio-administrativo tienen problemas y finalidades diversas (buscan desempeñar funciones diversas, para resolver problemáticas diversas) y que, por tanto, es razonable que sigan estrategias diversas.

En ciencias se sostiene que el objeto determina el método. Adaptando esa fórmula, aquí podríamos decir que el tipo de problemas determina el tipo de normas/sanciones. Es desde esta diversidad de problemas, finalidades y métodos que se capta el porqué de la consiguiente diversidad de garantías. Así, dando concreción a la fórmula, podría decirse que el tipo de problemas determina el tipo de normas/sanciones; mientras que el tipo de normas/ sanciones determina el tipo de garantías. De lo anterior se desprende la adhesión a un modelo de configuración gradual de garantías, sobre la base de una lógica de proporcionalidad directa entre las variables gravedad-de-la-sanción/garantía, cuanto menos como base para una diferenciación entre administrativo-sancionatorio y derecho penal ${ }^{12}$. Como lo ha planteado uno de sus más conocidos defensores:

"ni en todo el sistema jurídico debe haber las mismas garantías, ni en todo el sistema del Derecho sancionatorio tiene por qué haber las mismas garantías (...); pues las consecuencias jurídicas son sustancialmente diversas (...)"13.

${ }^{12}$ Cfr. Silva Sánchez, J.M, op. cit., nº 2, pp. 149, quien extiende la lógica de gradualidad y proporcionalidad para identificar zonas de diversa intensidad de garantías aun dentro del propio derecho penal (las ya célebres "dos velocidades”). Para ulteriores referencias bibliográficas en el contexto español e italiano, véase especialmente la nota $n^{\circ} 357$ del texto aquí citado. En nuestro medio, se ha pronunciado expresamente a favor de una aplicación proporcional de las garantías del derecho penal para el sancionatorio-administrativo (en lugar de lo que de otro modo sería un "traspaso en bloque de tales garantías”), Hernández, H, op. cit., nº 7, p. 449. En similar sentido, con referencia a la proporcionalidad sanción/garantía, Cordero Q., Eduardo, "El Derecho administrativo sancionador y su relación con el Derecho Penal”, en Revista de Derecho (Univ. Austral), 2012, vol. XXV, No 2, pp. 131-157, pp. 149-150, en el contexto de la distinción entre derecho penal nuclear y derecho penal colateral (siguiendo en ello la perspectiva abierta justamente en el citado trabajo de Silva Sánchez).

${ }^{13}$ Silva Sánchez, J.M, op. cit., $\mathrm{n}^{\circ} 2$, p. 151. 
En la misma línea, ahora desde el derecho administrativo y para el específico contexto de la tipicidad, se ha pronunciado también Eberhard Schmidt-Assmann, en sintonía con la jurisprudencia constitucional de su país de origen:

"los estrictos criterios por los que se rige la determinación de la ley penal (mandato de lex certa), establecidos en el artículo 103.2 [de la Constitución alemana], no son extrapolables a las leyes administrativas"14.

Antes de continuar con el desarrollo de esta sección, debo hacer dos advertencias, necesarias para no defraudar las expectativas del lector. En primer lugar, que este trabajo no pretende ocuparse de la antigua e inagotable cuestión sobre si la sanción penal y la administrativa tienen o no una misma naturaleza o fundamento, ya en un plano teórico o de lege ferenda, ya en sede positiva-constitucional ${ }^{15}$. Aquí interesan en cambio aspectos metodológicos -de razonamiento práctico-subyacentes a los diseños normativos en juego. Y con esto, la segunda advertencia; y es que el objeto de este trabajo no coincide con una valoración de la law E economics y su aporte al derecho penal ${ }^{16}$. El análisis económico del derecho sirve aquí solo de contexto para ponderar el tipo de variables y de razonamiento práctico subyacentes a las dos estrategias sancionatorias que aquí nos ocupan ${ }^{17}$. La law E economics nos interesa aquí, entonces, solo como especie de un género más amplio de aproximación al derecho (de estrategia de cara al derecho).

${ }^{14}$ Schmidt-Assmann, E., La teoría general, op. cit., pp. 205 ss., p. 207, agregando luego que "el Tribunal Constitucional Federal [alemán] ha advertido acertadamente del peligro que comporta una concepción exagerada según la cual toda norma debiera ofrecer en todos los sentidos certeza absoluta" [basándose en BVerfGE, 80,103 (108); y BVerfGE, 47, 327 (385 y 386)]. Es importante advertir en todo caso que este mismo autor ofrece criterios "moderadores", tendientes a instar por estándares superiores de determinación legal en el contexto administrativo tout court; a saber, en ámbitos connotados por inseguridad en los conocimientos del sector a regular (op. cit, p. 209); allí donde la Administración lleve a cabo una intervención imperativa o coercitiva en la esfera jurídica de los ciudadanos (op. cit, p. 211); y, en fin, allí donde la ley pueda exponer a terceros al poder normativo de entidades privadas o corporaciones sectoriales de base privada con insuficiente legitimidad democrática (op. cit, p. 211).

15 Sobre la materia, en nuestro medio, cfr. el trabajo pionero de Rodríguez Collado, Luis, "Bases para distinguir entre infracciones criminales y administrativas”, Revista de Derecho (PUCV), 1987, XI, pp. 117-163. De reciente, en dimensión teórica y constitucional, respectivamente, Cordero Q., Eduardo, "El Derecho administrativo...", op. cit., no 12, pp. 131-157; y Cordero Q., E. y Aldunate L., E., "Las bases constitucionales...”, op. cit, $\mathrm{n}^{\circ}$ 4, pp. 337-361. En lo demás, la referencia bibliográfica podría incluir a toda la manualística penal de nuestro medio.

${ }^{16}$ Una toma de posición crítica del rendimiento del análisis de la law E economics para el derecho penal puede leerse en Silva Sánchez, Jesús María, Política Criminal y Persona, Ed. Ad hoc, Buenos Aires, 2000, pp. 31-88 (cap. 2 = Eficiencia y Derecho Penal). Desde una perspectiva adherente al modelo, ampliamente y con bibliografía canónica de referencia, cfr. Cooter, Robert, Ulen, Thomas, Law and Economics, Addison Wesley-Longman, 3a ed., 2000, cap. 11.

${ }^{17}$ Como se verá, mi opinión es que solo una de ellas constituye propiamente una "estrategia". 
Pues bien: ¿qué tipo de razonamiento práctico se halla en las bases de la law $\varepsilon$ economics?

Introduzco un primer esbozo de respuesta a partir de una cita in extenso. Se trata de una consideración autobiográfica de Guido Calabresi ${ }^{18}$, formulada al recordar sus primeras impresiones tras la lectura del célebre Crime and Punishment de Gary Becker ${ }^{19}$. Así pues, Calabresi ofrece el siguiente recuento de su inicial perplejidad ante la tesis de Becker:

"En [Crime and Punishment] Becker describía el derecho penal simplemente como un mecanismo de atribución de precios, en el que la sanción por un delito debería ser el valor de la cosa robada, multiplicado por las posibilidades de no ser aprehendido; eso me parecía absurdo. Yo consideraba extraño que Becker -a quien yo imaginaría horrorizado si, en el contexto del derecho de propiedad, cualquiera pudiera estar autorizado para exigir tu reloj o tu casa a cambio de algo considerado como equivalente por una agencia estatal- pareciera decir precisamente eso para el derecho penal. Me dije, 'Becker no puede querer decir esto. Algo está mal con este análisis"”20.

Por cierto, si en lugar de la propiedad (del objeto robado) se considerase la vida o la libertad (moral, sexual, la que se quiera), la analogía entre derecho penal y mecanismo de asignación de precios resultaría ya no solo absurda, sino además horrorizante. ¿Podría acaso reconocerse en la pena del delito de homicidio el precio a pagar por la vida de una persona? ¿En la pena del delito de violación el precio a pagar por una prestación sexual no consentida?

Pero más allá de esta perspectiva crítica, ¿qué es lo que genera perplejidad de cara a este razonamiento? (me refiero al razonamiento originalmente atribuido por Calabresi a Becker).

Consideremos primero que Becker tiene en vista no tanto la perspectiva normativoprescriptiva de quien crea la regla de sanción, como la del destinatario de la misma; quien la recibe. Debido a que Becker tiene en mente un determinado tipo de agente (aquél que se desenvuelve en función de variables económicas, encaminado a maximizar su utilidad)

${ }^{18}$ Calabresi, Guido, "Remarks: The simple virtues of the Cathedral", en Yale Law Journal, vol. 106, 1996-1997, pp. 2201 ss., p. 2203.

19 Becker, Gary S., "Crime and Punishment: An Economic Approach", en The Journal of Political Economy, vol. 76, n.2, 1968, pp. 169-217.

${ }^{20}$ Calabresi, Guido, "Remarks...", op. cit., n ${ }^{\circ}$ 18, p. 2203: In that article, Becker described criminal law as a simple pricing mechanism in which the penalty for a crime should be the value of a stolen good multiplied by the chances of not getting caught. And that seemed silly to me. I found it odd that Becker-who I thought would be appalled if, in the property context, anyone were allowed to demand your watch or your land in exchange for what some state agency said it was worth-seemed to say just that in a criminal setting. I said, "Becker can't mean it. Something is wrong with this analysis". Como a continuación reconoce Calabresi, la atención a esa paradoja lo llevaría más tarde a dar con la distinción entre reglas de propiedad y reglas de responsabilidad (property rules y liability rules). 
puede concebir la norma como dirigida a disuadirlo con el tipo de motivaciones que lo mueven (en línea con sus sensibilidad, podríamos decir); es decir, con el ofrecimiento de un precio tan alto que -razonablemente- no quiera ser asumido por el agente interpelado ${ }^{21}$.

Pero además, y esto es interesante, considerando solo un extremo de la ecuación -el del destinatario de la norma- Becker no busca ofrecer mecanismos de asignación de precios (como luego advertiría Calabresi), sino sentar principios para una eficaz/razonable política pública en materia sancionatoria; mejor: se propone establecer las bases para una política pública razonable, mediante el derecho sancionatorio.

\section{II.C}

La idea de política - antes que la de derecho- ha sido así colocada en primer plano. Con ello quiero decir lo siguiente: no ya una respuesta adecuada al mérito del caso concreto (lo que es contingente), sino una respuesta adecuada en función del entorno, para el sistema.

¿Pero desde qué visión o concepción del derecho (sancionatorio) puede explicarse este tipo de aproximación "sistémica"? ¿Se aviene esta perspectiva a toda dimensión del problema?

Comencemos por lo primero. La orientación sobre la que descansa una pretensión semejante -la que hace suya el análisis económico- es, se sabe, una de orden consecuencialista; esto es, en la que la corrección de una solución -la justicia de un acto o la bondad de una acción- no se juzga por un valor intrínseco que ella realiza (porque justa/injusta; correcta/incorrecta; buena/mala $)^{22}$, sino en atención a las consecuencias que, en el mundo de lo sensible, ella trae ${ }^{23}$. Para esta perspectiva, una sanción habrá de considerarse ade-

${ }^{21}$ Se enfatiza que, como el propio Becker relataría en un trabajo preparado con motivo de la recepción del Premio Nobel de economía por su Crime and Punishment, la idea germinal de esta tesis -que reconoce en la sanción un precio, en un horizonte de racionalidad práctica- le vendría a propósito de una experiencia personal: el cálculo que se halló haciendo para sí mismo en un contexto en el que, apremiado por la necesidad de llegar puntualmente a una actividad académica, pudo elegir entre buscar un estacionamiento autorizado (con el riesgo de retrasar su arribo), o bien estacionar en un espacio disponible pero no autorizado (con el respectivo riesgo de asumir una multa): cfr. Becker, Gary S., "Nobel Lecture: The Economic Way of Looking at Behavior", en The Journal of Political Economy, vol. 101, n. 3, 1993, pp. 385 ss., pp. 389-390.

${ }^{22}$ Martin Buber ofrece una definición de ética en esta línea (ética en sentido tradicional): "Por lo ético en este sentido estricto entendemos el sí y el no que el hombre da a la conducta y acciones que le son posibles, a la radical distinción entre ellas que las afirma o las niega, no de acuerdo con su utilidad o perjuicio para los individuos o para la sociedad, sino de acuerdo con su valor y su disvalor": Buber, Martin, "Religión y Ética”, en ID., Eclipse de Dios, Ed. Nueva Visión, Buenos Aires, 1970, p. 86.

23 Cfr., críticos de la perspectiva consecuencialista en el plano de la teoría ética, Grisez, Germain "Against Consequentialism”, en American Journal of Jurisprudence, vol. 23, 1978, pp. 21 ss.; igualmente, Finnis, John, Moral Absolutes: Tradition, Revision and Truth, Washington, 1991, siendo también de interés - para este específico punto- la recensión de Alasdair MacIntyre al citado texto de John Finnis, en MacIntyre, Alasdair, "Review", en Ethics, vol. 103, N. 4, Jul, 1993, pp. 811-812. Cfr. igualmente, Spaemann, Robert, Concetti morali fondamentali (Trad. Luca F. Tuninetti del original Moralische Grundbegriffe, Ed. Beck, 1986), Ed. Piemme, Casale Monferrato, 2001, pp. 73-85; y Spaemann, Robert, Felicità e benevolenza (Trad. Matteo Amori del original Glück und Woblwollen: Versuch über Ethik, Ed. Ernst Klett, 1989), Ed. Vita e Pensiero, Milán, 1998, pp. 155-169. 
cuada o inadecuada, no tanto por su aporte a la solución del caso concreto -en términos de justicia retributiva o conmutativa- sino en razón de su aporte a la mejora del entorno o del sistema al que el caso a juzgar pertenezca. Ya se sabe, se sacrifica el particular en aras de lo general. Lo individual en pos de lo común.

Esta orientación busca entonces "mejorar el mundo" (mira al futuro, al progreso) ${ }^{24}$, mediante la validación de acciones consideradas valiosas no porque lo sean, sino porque sus consecuencias lo son para una realidad que trasciende al caso; esto es, el sistema, el entorno ${ }^{25}$.

¿Pero pueden el sistema o el entorno mejorarse mediante el derecho sancionatorio? ¿Qué mundo es ese que puede mejorarse? ¿Y cómo han de estructurarse unas normas idóneas para la mejora del sistema?

\section{II.D}

Lo dicho hasta aquí ofrece ya una clave de respuesta preliminar. Por de pronto, la conveniencia de una acción supondrá una ponderación de lo que esta trae aparejado -esperablemente- en el mundo de lo sensible; mejor, en el mundo de lo cuantificable, de lo conmensurable. Esta dimensión del mundo puede asociarse a "lo económico", en contraposición a "lo normativo". Este enfoque consecuencialista no puede en cambio tratar con unidades de valor no conmensurables, no cuantificables ${ }^{26}$. Así, muy bien podrá plantearse que la atribución de $x$ multa o $x$ sanción de inhabilitación (traducible en términos de costos) es una adecuada respuesta (porque mejora el sector sobre el que impacta) a una sustracción de valor equivalente a $x$; pero jamás podrá plantearse -es lo que estoy aquí defendiendo- que la pena sufrida en términos de privación de libertad es

${ }^{24}$ En el marco de las tradicional discusión sobre el sentido de la pena (prevención/retribución), la perspectiva coincide con la fórmula consecuencialista/relativa del ne peccetur (en contraposición a la noconsecuencialista/absoluta quia peccatum est): cfr. Roxin, Claus, Derecho Penal. Parte General. Tomo I, Ed. Civitas, Madrid, 1997, p. 85 (\$3.2.11); cfr. igualmente, Bustos Ramírez, Juan, Manual de Derecho Penal. Parte General, Ed. Ariel, Barcelona, $3^{\mathrm{a}}$ ed., 1989, p. 23; y Cury, Enrique, op. cit., n ${ }^{\circ}$ 7, p. 64. Un balance "dialéctico" entre las diversas perspectivas en juego se halla en Roxin, Claus, "Sentido y límites de la pena estatal”, en Problemas Básicos del Derecho Penal (Trad. Diego M. Luzón Peña), Ed. Reus, Madrid, 1976. pp. 11-36.

${ }^{25}$ En un horizonte hermenéutico, un enfoque semejante se asocia al método de argumentación orientada a las consecuencias, el que soslayaría la atención directa a las dimensiones de valor intrínsecas al problema interpretativo en cuestión; en este sentido, cfr. Mengoni, Luigi, Ermeneutica e dogmatica giuridica, Ed. Giuffrè, Milán, 1996, p. 97, quien además identifica a Aristóteles como precursor de este método, para escenarios de insalvable incertidumbre valorativa: "Con este método, ya recomendado por Aristóteles, la congruencia axiológica de una decisión valoradora se transforma en una función de su justificación basadas en las consecuencias sobre los comportamientos sociales". (Mengoni, op. cit., p. 97) [¿Y qué es lo que recomendaba Aristóteles?]: "cuando dos o más objetos son similares y no estamos en condiciones de advertir la preeminencia de uno sobre otro, se pueden observar las consecuencias; el objeto del que se sigue un bien mayor, es preferible; si en cambio las consecuencias corresponden a males, más deseable es el objeto del que deriva un mal menor" (Organon, Tópicos, 117 a, citado por Mengoni en op. cit. p. 97, nota $n^{\circ} 16$ ).

${ }^{26}$ En este sentido, con específica referencia al análisis económico del derecho como incapaz de integrar valores, cfr. Silva Sánchez, J.M., Política Criminal y Persona, op. cit., no 16, p. 80. Ya en el plano de la teoría moral, cfr. Grisez, G., op. cit., $\mathrm{n}^{\circ} 23$, pp. 21 ss. En lo demás, siendo este uno de los ejes de la crítica tradicional al consecuencialismo, puedo remitirme a la literatura citada en nota ${ }^{\circ} 23$ de este texto. 
una respuesta adecuada (en un plano de "mejores consecuencias" para el entorno social) a un ultraje de tipo sexual, un atentado a la vida, a la libertad de pensamiento, etc. Pues ¿qué "cálculos de consecuencias" pueden exhibirse para defender un juicio en este segundo supuesto? Ninguno, a mi parecer, tratándose -como se ha dicho- de unidades de valor no conmensurables.

Pues bien, a esta lógica consecuencialista -que como se ha visto parece en principio plausible en un escenario en el que se comparen dimensiones conmensurables (económicas) - se opone la perspectiva no consecuencialista. Se trata aquí de la idea de que una acción humana -en este caso la actividad en virtud de la que se dicta una norma o se atribuye responsabilidad y sanción (emanación y aplicación normativa)- ha de considerarse valiosa en cuanto aparece como respuesta/retribución a un acto no valioso, considerado en sí mismo ${ }^{27}$. Así, para este enfoque-que podemos llamar también "tradicional”- una conducta ha de prohibirse y sancionarse porque en sí reprochable, y no (necesariamente) porque su prohibición y sanción introduzcan consecuencias o mejoras para el entorno, para el sistema. Si ello sucede, tanto mejor, pero será una mera externalidad de una adecuada valoración, y no la razón fundamentadora de dicha valoración.

En otras palabras, para esta perspectiva tradicional, una norma (o aplicación de una norma) no ha de considerarse oportuna en cuanto idónea para mejorar el mundo (como postula el consecuencialismo), sino que el mejoramiento del mundo constituye una consecuencia deseable de una norma (o interpretación de una norma) que puede ser reconocida como oportuna por razones intrínsecas a la valoración del objeto sobre el que recaen ${ }^{28}$.

Ahora bien, ¿cuáles son esas razones? Por de pronto, en el plano de la creación normativa penal, la identificación de un fenómeno conductual como grave y socialmente lesivo (no deseable, por tanto), de modo que frente a él pueda plantearse como razonable y justa una reacción punitiva de entidad superior (subsidiaria y proporcionada) ${ }^{29}$. En el campo de la aplicación de la normativa penal, la identificación de un hecho como subsumible en una norma de prohibición y sanción. Todo lo anterior, en un escenario de primacía de la legalidad.

Pues bien, podemos ahora volver al pasaje relativo a Becker y a la inicial perplejidad de Calabresi. Quien cree ver en la ley penal solo una amenaza -en clave de disuasiónasume una perspectiva consecuencialista, a-normativa. Según esta perspectiva, la ley (penal) aparecería como un mero enunciado anticipador de eventuales consecuencias (la internalización de un costo, según la enseñanza canónica de la law $\mathcal{E}$ economics) ${ }^{30}$, en un

${ }^{27}$ Cfr. Buber, M., op. cit, $\mathrm{n}^{\mathrm{o}} 22$, p. 86.

${ }^{28}$ En esta formulación estoy parafraseando a Spaemann, R. Felicità e benevolenza, op. cit., n 23, p. 167.

${ }^{29}$ En la materia, cfr. Hassemer, Winfried y Muñoz Conde, Francisco, Introducción a la Criminología $y$ al Derecho penal, Tirant lo Blanch, Valencia, 1989, pp. 49-96; igualmente, Roxin, C., Derecho Penal, op. cit., $\mathrm{n}^{\circ} 24$, pp. 49 ss (§2/1 ss), recogiendo las tesis cualitativas para la distinción entre "hechos punibles y contravenciones".

${ }^{30}$ Cfr. Becker, G., "Crime and Punishmente”, op. cit., pp. 169 ss.; igualmente, con aplicaciones para importantes sectores del derecho, los muy conocidos trabajos de Calabresi, Guido, The Costs of Accidents. A Legal and Economic Analysis, Yale University Press, New Haven, 1970, pp. 144 ss.; y de Easterbrook, Frank 
contexto en el que nada hay de objetivo o predeterminado fuera del "consenso-amenaza" que se instaura mediante la promulgación de la ley penal; cual si se tratara de un regateo sin presupuestos objetivos y en el que la dimensión moral-normativa del agente quedase excluida. Un regateo del tipo: Usted me dice que si hago $X$ podrá sucederme $Z$ (es decir, deberé asumir un determinado costo). Pues bien, tomo (o declino\} su "oferta": pues he considerado que la probabilidad y pérdida implícita en $Z$ es alta (o baja) si consideraba la probabilidad y ganancia implícita en mi objetivo $X$.

\section{II.E}

Con todo, es evidente a cualquiera la realidad valorativa subyacente. Ella emerge tras la siguiente pregunta: ¿por qué asocia usted un costo a una determinada conducta, en lugar de, por ejemplo, un premio? ¿No supone acaso eso un determinado juicio de valor en términos de qué ha de hacerse y qué no ha de hacerse? (o bien, desde el punto de vista del Estado, un juicio sobre qué ha de favorecerse y qué ha de desalentarse). El asunto es iluminado ulteriormente si se considera una perspectiva normativa-preceptiva. En efecto, la ley no solo anticipa una eventual consecuencia, sino que también manifiesta la total desaprobación del hecho-presupuesto en cuanto actividad deliberada o negligente del destinatario. La ley no solo dice: si usted hace X (eventualmente) le sucederá $Z$. Más bien, antes que eso, dice: usted no debe hacer X. No es mi voluntad que usted haga $X$. Repruebo que usted haga X.

La coexistencia de dos visiones tendencialmente contrapuestas en la identificación del sentido y finalidades de una determinada prohibición/sanción es captado con claridad por Robert Cooter en su trabajo "Precios y Sanciones"31.

"Los profesores de derecho tradicionalmente ven el derecho como un set de obligaciones respaldadas por sanciones o comandos respaldados por amenazas. En contraste, los economistas tienden a ver el derecho como un set de precios fijados por la autoridad. A cada una de estas perspectivas le corresponde una ceguera característica. La perspectiva legal impide ver a los abogados que los agentes estatales no pueden regular la economía de modo eficiente emanando órdenes. En cambio, ellos deben confiar en instrumentos legales similares a los precios. A la inversa, la perspectiva económica es ciega a la dimensión distintivamente normativa del derecho, percibiendo la sanción por hacer lo que está prohibido solo como el precio por hacer lo que está permitido. En síntesis, el análisis económico del derecho carece de una clara consideración de las sanciones, mientras que la tradición legal de una correcta consideración de los precios" 32 .

\footnotetext{
H. y Fischel, Daniel R., The Economic Structure of Corporate Law, Harvard University Press, Cambridge (MA, EE.UU.), 1991, pp. 283 ss.

${ }^{31}$ Cooter, Robert, "Prices and Sanctions", en Columbia Law Review, vol. 84, 1984, pp. 1523-1560.

32 Cooter, R., "Prices”, op. cit., nota precedente, p. 1523: Scholars of jurisprudence traditionally view law as a set of obligations backed by sanctions, or commands backed by threats.' In contrast, economists tend to view law
} 
Pero detengámonos en un pasaje intermedio de la cita:

"La perspectiva legal impide ver a los abogados que los agentes estatales no pueden regular la economía de modo eficiente emanando órdenes" ${ }^{33}$.

¡Toda la razón! Pero Cooter puede afirmar esto porque parece no advertir que no todos los agentes tienen una aproximación consecuencialista de su quehacer (o no deberían tenerla, al menos). Es decir, no todos los agentes se trazan como objetivo la regulación de la economía; o bien, más modestamente, la mejora de un sector o sistema (y puede ser peligroso cuando así lo pretenden, olvidándose del mérito del caso concreto; más aún si carecen de las herramientas, experiencia y visión de conjunto necesarias como para incidir regulativamente en el sector o sistema; pero sobre esto volveré al cierre de este trabajo).

\section{TOMA DE POSICIÓN. LA CONVENIENCIA DE DISTINGUIR ENTRE TIPICIDAD PENAL Y LEGALIDAD ADMINISTRATIVA: EL MARCO LEGAL ADMINISTRATIVO-SANCIONATORIO}

III.A

Llegados a este punto de la argumentación, es posible extraer una primera conclusión operativa. Lo digo ahora en extrema síntesis, acortando varios pasajes que posiblemente harían más clara la afirmación. En el área penal se lidia con inputs y outputs tendencialmente no conmensurables, en cuanto vitales-personales. A lo menos dos dimensiones sintetizan esta inconmensurabilidad. Por una parte la idea de estigma y, por la otra, la privación de libertad (incluso potencial) ${ }^{34}$. Pues bien, si lo que está en juego es, como se ha

as a set of official prices. 2 Associated with each of these viewpoints is a characteristic blindness. The jurisprudential perspec-tive blinds lawyers to the fact that officials cannot regulate the economy efficiently by giving orders. 3 Instead, they must rely upon legal instruments similar to prices. Conversely, the economic perspective is blind to the distinctively normative aspect of law, viewing a sanction for doing what is forbidden merely as the price of doing what is permitted. In brief, the eco-nomic analysis of law lacks a clear account of sanctions, and the jurisprudential tradition lacks a good account of prices.

${ }^{33}$ Cooter, R., "Prices", Op. cit., p. 1523: the jurisprudencial perspective blinds lawyers to the fact that officials cannot regulate the economy efficiently by giving orders.

${ }^{34}$ Con referencia a la dimensión comunicativa-social, el estigma; relativa a lo físico-moral, la privación de libertad. Nótese que no es decisiva solo aquella privación efectivamente ejercida, sino también aquella normativa-potencial (la mera posibilidad de afectación). Es decisivo en la especie ese poder de constricción que el derecho penal confiere a la autoridad sobre la persona, sobre su cuerpo. En este contexto, no puede dudarse del diverso nivel de vulnerabilidad personal que plantea el derecho penal respecto del administrativosancionatorio. Que desde siempre el análisis económico vea una diferencia en el plano de la transferibilidad/ no transferibilidad de la sanción administrativa/penal, no es más que un corolario de la dimensión vitalpersonal que solo entra en juego en el derecho penal. Las distinciones que esta nota supone son someramente tratadas en la prevención Colombo-Correa, considerando Tercero, en STC Rol No 480 de 27 de julio de 2006. Desde esta perspectiva debería también fundarse un rechazo a todo régimen de conversión de la sanción administrativa en formas de privación de libertad. Al respecto, cfr. STC N ${ }^{\circ} 1518$ de 21 de octubre de 2010 
dicho, vital-personal entonces no es aceptable que las autoridades se valgan de ello para la consecución de finalidades externas $(=\text { mejoras del sistema })^{35}$. Lo anterior no solo no es aceptable; en rigor no es tampoco posible, como se ha dicho más arriba ${ }^{36}$.

La situación en el campo administrativo se plantea en cambio diversa. En la medida que se trata allí de dimensiones tendencialmente conmensurables (y que normalmente no se ven directamente afectadas dimensiones vitales-personales, como por ejemplo cuando el regulado es una persona jurídica), la perspectiva consecuencialista -la búsqueda de mejoras para el entorno más allá del caso concreto- asume legitimidad y se vuelve plena de sentido. ¿No es acaso lo propio del legislador o regulador administrativo dictar normas con miras a obtener de ellas mejoras sectoriales? ¿Y no es acaso lo propio de la autoridad que interpreta dichas normas el dar con outputs funcionales a la mejora del sector regulado? (evitando así fenómenos de sobredisuasión [over-deterrence]; fomentando la competencia; incentivando la inversión "socialmente responsable y generadora de riqueza”, etc.) ¿Hacen eso, en cambio, un legislador penal, un juez penal o un fiscal del ministerio público? Mejor: ¿deben/pueden hacerlo? Aquí he defendido que no pueden -de hecho- y que en todo caso no deberían intentarlo.

Es posible responder ahora al problema inicial; es decir, la conveniencia o no de un principio de tipicidad estricto en el campo administrativo. Como he anticipado, aquí se defiende su inconveniencia. La legalidad debería bastar en este campo, manifestada en un marco legal administrativo-sancionatorio ${ }^{37}$.

Pues bien, si de lo que se trata es de mejorar las condiciones de un entorno mediante normas -que se suman a aquellas medidas introducidas por agentes económicos, desde afuera del derecho- entonces los estándares son bienvenidos, antes que las reglas estrictas. La autoridad administrativa -ya como ente creador de reglas, ya como ente aplicador de sanciones- requiere un marco de flexibilidad, adaptativo, para la consecución de fines más allá del caso concreto. Lo anterior tiene además la ventaja de ofrecer un espacio

(caso ISP-art.169 CSan, en materia de convertibilidad de la sanción administrativa). En lo demás, son de interés los criterios y subcriterios de la jurisprudencia de la Corte Europea de Estrasburgo para discernir si se está ante una sanción/procedimiento penal, poniendo en discusión la denominación del derecho nacional en discusión: al respecto, con referencia al leading case Engel y otros contra Holanda, cfr. Bernardi, Alessandro, "Nessuna pena senza legge”, en Bartole, E, Conforti, B. y Raimondi, G. (Dir.), Commentario alla Convenzione Europea per la tutela dei diritto dell'uomo e delle libertà fondamentali, Cedam, Padova, 2001, pp. 249-306, pp. 256259; y Treschsel, Stefan, Human Rights in Criminal Proceedings, Oxford University Press, 2005, pp. 16-18.

${ }^{35}$ El argumento kantiano de no instrumentalización del individuo es muy conocido: cfr. Roxin, C., "Sentido y límites", op. cit. pp. 18 y 19.

${ }^{36}$ Cfr. al respecto, muy ingenioso en su argumentación contra las teorías de la prevención, Lewis, Clive S., "The Humanitarian Theory of Punishment", en ID., God in the Dock: Essays on Theology and Ethics, Eerdmans Publishing, 1970, pp. 287 ss. (originalmente publicado en 20 ${ }^{\text {th }}$ Century: An Australian Quarterly Review, 1949, vol. III, No 3, pp. 5-12).

${ }^{37}$ Quizás, para evitar la asimilación, ya en un plano lingüístico habría que dar con una voz funcionalmente equivalente a la de "tipo" (traducción hispano-dogmática del alemán Tatbestand) para aludir a lo que se viene en denominar como "tipo administrativo". Aquí se ha ofrecido la noción de marco legal administrativosancionatorio, que, dicho sea de paso, no deja del todo conforme al suscrito. 
de amplitud suficiente como para favorecer adaptabilidad, en escenarios dinámicos, cambiantes, complejos y fragmentarios (como suele caracterizarse el sector económico). Como afirmara Hart:

"A veces se advierte desde un comienzo que la esfera a ser controlada jurídicamente es un campo en el que las características de los casos individuales variarán tanto en aspectos socialmente importantes pero impredecibles, que la legislatura no puede formular útilmente por anticipado reglas generales para ser aplicadas de caso a caso sin nuevas directivas oficiales. En consecuencia, para regular tal esfera la legislatura establece guías muy generales y delega en un cuerpo administrativo creador de reglas, familiarizado con los diversos tipos de casos, la tarea de modelar reglas adaptadas a las especiales necesidades de estos" 38,39 .

Si el modelo de regulación administrativa que aquí se ha esbozado puede caracterizarse como "vidente", "orientado a finalidades de sistema" (mientras que el de la tipificación penal no debe serlo, al menos no en primera línea y no en desmedro del amenazado con la pena), entonces se advierte la necesidad de que las normas administrativas estén dotadas de una textura lo suficientemente holgada -mejor, conscientemente abierta, más allá de la inherente apertura de la textura del lenguaje ${ }^{40}$ - como para posibilitar márgenes de movimiento en la conducción "vidente" del consecuencialista inspirado por el ideal de

${ }^{38}$ Hart, H.L.A. El concepto de derecho, op. cit., p. 163 (la cita se halla en la p. 131 de la 2da. Edición en idioma original, supra citada en nota $n^{\circ} 8$ ). Cfr. también, Tiedemann, Klaus, Manual de Derecho Penal Económico, Tirant lo Blanch, Valencia, 2010, pp. 107 ss., quien reconoce la funcionalidad de las cláusulas generales en el campo económico, en cuanto su amplitud "posibilita una adaptación a los cambios de las concepciones y los contextos, sin tener que cambiar la ley” (tomando luego posición a favor del recurso a interpretaciones restrictivas en el contexto estrictamente penal).

${ }^{39}$ Precisamente este tipo de consideraciones habrían inspirado la reforma (despenalizadora) en materia de ilícito monopólico, en virtud de la Ley $N^{\circ} 19.911$. En efecto, la necesidad de ofrecer un espacio normativo más elástico -en atención a las características particulares del sector- habría condicionado la opción a favor del ilícito administrativo (descartando el ilícito penal). De esta decisión legislativa se desprende una adhesión al modelo de tipicidad diferenciada entre el penal y el administrativo. Como puede leerse en el respectivo Mensaje Presidencial (132-346, 17 de mayo de 2002, boletín No 2.944-03): "Todo tipo penal debe describir las conductas que sanciona de manera precisa, de forma que los sujetos a los que se dirige la norma tengan la certeza de aquello que está prohibido por el legislador.

Sin embargo, el escenario actual en el que se desenvuelven los agentes económicos es complejo, por lo que es importante no introducir reglas que señalen per se las conductas que constituyen atentados en contra de la libre competencia. La experiencia mundial indica que hoy cada caso debe ser estudiado en su propio mérito, de acuerdo con sus complejidades y particularidades. Por estos motivos, resulta aconsejable mantener una norma amplia con ejemplos básicos, para que los integrantes del organismo encargados de conocer las causas decidan, de acuerdo con el caso concreto, qué conducta constituye un atentado a la libre competencia.

Sin embargo, este enfoque es incompatible con la existencia de una figura penal, en donde la especificación del tipo es un requisito ineludible, so pena de vulnerar la garantía constitucional establecida en el inciso final del número 3 del artículo 19 de nuestra Constitución”.

${ }^{40}$ Estoy por cierto parafraseando de Hart, H.L.A. El concepto de derecho, op. cit., no 8, pp. 158-159 (la referencia se halla en la p. 127-128 de la 2da. edición en idioma original, supra citada en nota $\mathrm{n}^{\circ} 8$ ). 
mejora del sistema. No entonces la camisa de fuerza que se esperaría de los tipos penales, sino una zona, un marco acotado en donde desplazarse.

La diferenciación aquí defendida podría ilustrarse recurriendo a la imagen del radio y la circunferencia. Piénsese entonces en la decisión legislativa (penal o sancionatoriaadministrativa que sea) como en un centro-pivote; a dicho hito puede atarse una cuerda, para representar el nivel de movilidad o desplazamiento permitido al intérprete desde el centro (es decir, el alcance de lo prohibido y de las consecuencias jurídicas asociadas a la infracción). La tesis es entonces que el administrativo-sancionatorio requiere una cuerda considerablemente más extensa que el penal, de modo que el radio de acción se amplíe, proporcionadamente. La mayor holgura de la circunferencia así conformada incrementa el rendimiento de una lectura orientada a finalidades de sistema.

Podría con todo objetarse que esa lectura instrumentalizaría a los regulados en pos del sistema (la misma objeción que hemos planteado rechazando una lectura consecuencialista para el derecho penal). Esa objeción no da en el blanco, al menos en la medida que el administrativo-sancionatorio se mantenga en los límites hasta ahora conocidos, sin que se le concedan poderes o outputs propios del penal; es decir, que colisionen con dimensiones vitales-personales no conmensurables Si las consecuencias jurídicas que arriesgan los regulados se mantienen en el campo de lo conmensurable -de lo preferentemente económico- entonces la objeción no debería ser de recibo ${ }^{41}$.

De cualquier modo debe ser claro que el espacio de aplicación consecuencialista no puede ser ilimitado ni mucho menos. Ha de tratarse de una circunferencia con contornos definibles: ni el centro-pivote puede faltar (ley), ni la cuerda asociada al radio de acción puede ser ilimitada. En efecto, lo prohibido y las consecuencias jurídicas deben aparecer como determinables. Si acaso, como ya se ha expuesto abundantemente, no se adhiere aquí a la noción de "tipicidad administrativa" (en sentido vigoroso, penal), ello de ningún modo significa que no se comparta la exigencia de un marco seguro de legalidad que funde el poder sancionatorio. La legalidad es impostergable ${ }^{42}$.

Puede entonces, ya para cerrar esta sección, responderse a la pregunta sobre cuál es ese marco suficiente de legalidad. La pregunta coincide con la necesidad de hallar un

${ }^{41} \mathrm{Mi}$ opinión es que la concesión de nuevos poderes en el marco del administrativo-sancionatorio introduce un "costo" para los aplicadores en términos de mayores garantías. En efecto, no pueden pretenderse mayores poderes sin reconocerse mayores garantías. La fórmula de directa proporcionalidad gradual "poder/ sanción/garantía” tiene que jugar un rol también aquí. Si acaso poderes de allanamiento de morada u otros que afecten a las comunicaciones pueden considerarse "no conmensurables", es algo que aquí no puede quedar zanjado, si bien manifiesto desde ya mi resistencia a otorgar poderes autónomos semejantes a la administración. Mecanismos de control externo -judicial- parecen aquí indispensables.

42 Criticable es en este contexto la sentencia de casación de la Tercera Sala de la Corte Suprema, Rol No 7397-2012, dictada el 16 de septiembre de 2013 (caso Essbio), en cuanto sostendría la suficiencia del artículo 67 del Código Sanitario como base para imponer sanciones administrativas. Considérese que la citada disposición solo otorga un área de tarea o finalidad para la autoridad sanitaria: ni deberes para los administrados, ni poderes sancionatorios pueden desprenderse de dicha norma. No se ha tenido a la vista la sentencia de reemplazo, pero el tenor de la sentencia de casación es lo suficientemente claro como para merecer este comentario crítico. 
límite, más allá de ello la elasticidad del modelo aquí defendido pueda considerarse irrazonable, ilegítima ${ }^{43}$. Lo anterior, ya porque incapaz de poner límites al poder de la autoridad, ya porque incapaz de orientar al regulado ${ }^{44}$.

Pues bien, en mi opinión ha de considerarse suficiente una ley que identifique uno o más deberes del regulado (representativos de estándares de comportamiento razonablemente vinculables a finalidades de protección claramente identificables en la legislación del sector de que se trate $)^{45}$, mismos cuya infracción se amenace-siempre por el legislador-con determinado rango de sanciones (no penales $=$ no directamente incidentes en la dimensión personal-vital) ${ }^{46}$. Si luego, mediante normativa infra-legal, la administración desarrolla los contornos de los deberes legales cuya infracción genera sanción, entonces eso no puede verse como una vulneración de la "tipicidad administrativa", sino, al contrario, como un esfuerzo de precisión en interés del regulado. Esto último, en la medida que la regulación infra-legal aparezca como "subconjunto" del "conjunto" legal, y no como una extensión defraudadora de la legalidad.

Esta articulación es aquí identificada con la idea de marco legal administrativosancionatorio $^{47}$. A mi modo de ver, la posición adoptada por nuestra jurisprudencia constitucional en materia de "tipicidad administrativa" se deja describir aproximadamente en los términos que he expuesto recién, al menos a partir de las sentencias STC No 480 y STC No 479 (caso Eléctricas).

${ }^{43}$ Un problema análogo se plantea para la propia tipicidad penal, en un espacio ya más acotado de indeterminación (idealmente), representado por tipos que tienden a estructurarse como rules y no como standards. Un panorama de soluciones ofrecidas en ese contexto por la dogmática y la jurisprudencia constitucional alemanas puede verse en Roxin, C., Derecho Penal, op. cit., pp. 171-174 (\$5, nm 68-76). De destacar aquí el que el Tribunal Constitucional federal de Alemania haya admitido que "las exigencias de determinación legal crecen junto con la cuantía de la pena prevista en el tipo”, frente a lo que Roxin se muestra crítico: op. cit., p. 171 ( $\$ 5, \mathrm{~nm} 68)$, con referencia a BVerfGE 14, 245 ss (26).

${ }^{44}$ Para estar a las dos variables (¿alternativas?) que darían contenido al fundamento de la garantía de tipicidad, según ha expuesto entre nosotros Weezel, Alex Van, op. cit, nº 4, pp. 5-19.

${ }^{45}$ Cfr. Cordero Q., E. y Aldunate L., E., "Las bases constitucionales”, op. cit., no 4, pp. 357-358, con referencia a los deberes de actuación impuestos a los regulados.

46 Sobre esta base general es que se discrepa de Alcalde, E., La responsabilidad de los directores, op. cit., $\mathrm{n}^{\circ}$ 4, pp. 338-339, allí donde este autor considera insuficiente el marco legal sancionatorio del artículo 41 de la Ley de Sociedades Anónimas.

${ }^{47}$ De similar manera lo caracterizaría ya Weezel, Alex Van, op. cit., no 4, pp. 159 ss., esp pp. 168 y 201, aunque discrepando del modelo matizado o flexibilizado de tipicidad establecido por dicha jurisprudencia, al que este autor considera como "una aplicación analógica de la garantía constitucional de tipicidad” (p. 168), representando "un estándar inferior a este, pues se conforma con que la ley describa un deber de conducta, cuya infracción puede ocurrir de muchos modos diversos no tipificados" (p. 168). Si los planteamientos ofrecidos en este trabajo entregan algunas pocas razones para discrepar de esta última valoración, entonces su propósito se habrá conseguido con creces. Es posible en todo caso que la valoración negativa que dicho autor asigna a la respectiva jurisprudencia constitucional no se deba tanto a un rechazo a la solución gradual o proporcional en sede de garantía, como a la inconsecuencia que representa el uso de la voz "tipicidad" (administrativa), cuando en realidad con ella no se quiere ya significar nada comparable a la tipicidad (penal). 
III.B

Hay otro orden de razones para hacer las distinciones aquí defendidas. Mientras que en el campo penal la sujeción del regulado a la prohibición-sanción es normalmente vinculante en sentido fuerte, en el campo administrativo dicha sujeción se da en un sentido débil. Me explico.

En el campo penal la persona se encuentra vinculada a la prohibición-sanción por el solo hecho de "ser" (cuanto menos imputable) y "hallarse" (en el territorio nacional). A la persona (imputable habitante de la República) no cabe decidir si adherir o sustraerse a la regulación aplicable al homicidio, al secuestro, a la violación, etc. La regulación -prohibición y sanción- está allí, implacable, con toda prescindencia de la voluntad de adhesión del destinatario. Esto suele en cambio no ocurrir en el sancionatoriogubernativo, al menos allí donde se trate de la regulación de subsistemas al que los agentes -normalmente unidades productivas- hayan adherido voluntariamente; $y$, por tanto, teniendo ocasión de ponderar las ventajas y riesgos de la adhesión al subsistema en calidad de regulado ${ }^{48}$. Es posible que mi perspectiva esté sesgada por la atención a los sectores económicos dotados de mayor regulación -piénsese en el mercado de valores o en el mercado financiero tout court, entre otros-, pero creo que mi afirmación es válida cuanto menos para todo el sancionatorio-gubernativo.

Pues bien, de esta diversidad de vinculación -tendencialmente involuntaria, en un caso, y tendencialmente voluntaria en el otro- se desprende una diversa posibilidad de captación del contenido normativo de la regulación. Así, mientras el presupuesto de conocimiento de la prohibición constituye casi una ficción en el campo penal, en el campo administrativo ello constituye normalmente una realidad; antes bien, casi una condición para el exitoso desempeño de la actividad que el agente se ha propuesto desarrollar ${ }^{49}$.

${ }^{48}$ Es interesante trazar un paralelo con los modelos sancionatorios de naturaleza privada, tan típicos en contextos gremiales y muy comunes en el seno de actividades deportivas: ¿Acaso las sanciones allí son sustancialmente inferiores a las del administrativo-sancionatorio? Como sabemos, las multas son significativas y las inhabilitaciones pueden incluso ser vitalicias (como ha sucedido con connotados deportistas nacionales). ¿Qué es lo que las hace tan distintas a las imperantes en un subsistema administrativo al que libremente se ha adherido? Nótese que ni en uno ni en otro caso pueden siempre los regulados elegir a las autoridades, ni determinar las reglas, de modo que no es un diverso grado de "autorregulación” el que explica una diferencia, que - de hecho- se hace.

${ }^{49} \mathrm{La}$ consideración del destinatario de la norma como variable para efectos de calibrar las específicas exigencias de determinación del la ley penal puede ya considerarse un patrimonio de la jurisprudencia europea de derechos humanos, en el marco de la interpretación del artículo $7^{\circ}$ de la Convención Europea y la garantía de tipicidad penal. Al respecto, cfr. Bernardi, A., "Nessuna pena...", op. cit, no 34, pp. 262-263, haciendo ver que "la claridad y precisión de las normas se valoran teniendo en consideración las características de los sujetos destinatarios, especialmente allí donde estos tengan un conocimiento específico de los riesgos inherentes al ejercicio de las actividades previstas por la ley, de tal modo de estar en condiciones de distinguir entre actos lícitos y actos prohibidos" (con ref. a Comisión, 4 de diciembre de 1978, X. c. Austria, DR, 16, p. 143 ss.). Por su parte, la atención al tipo de destinatario y a su contexto (regulado o no) juega un papel en el tratamiento del error de probibición en derecho penal, elevándose los estándares de exigencia (asumiendo vencibilidad del error) respecto de quiénes tendrían "motivos para cerciorarse", uno de ellos correspondería 
Dicho en términos más plásticos: ¿puede acaso dudarse que para un ciudadano común el tipo penal -aún el más preciso y coherentemente interpretado- ofrece un escenario de menor accesibilidad cognitiva que el que para un regulado ofrece una disposición sancionatoria-administrativa, incluso si flexible y maleable en su interpretación? Al primero no se impone su estudio como condición de éxito para el desarrollo de su proyecto vital; al segundo sí se le impone -razonablemente- como condición de éxito para el desarrollo de su proyecto organizacional ${ }^{50}$. Podría objetarse que la menor accesibilidad del tipo penal se compensa con la mayor accesibilidad de su contenido de injusto ético-social (la idea de mala in se); pero a dicha objeción puede responderse argumentando que ello es válido solo para el núcleo del derecho penal, mientras que no lo es para esa creciente masa periférica de tipologías penales (mala probibita).

III.C

A modo de cierre, casi una digresión. Una nota final, relativa al modelo jurisdiccional imperante en el sancionatorio-administrativo. La observación es la siguiente: si el diseño administrativo-sancionatorio obedece a un esquema de relativa mayor flexibilidad en sede de tipicidad (como aquí se ha defendido, haciendo ver su conveniencia), entonces, una inadecuada dosis de judicialización puede llevar a resultados no deseables en ese terreno. Lo anterior, en la medida que, tratándose de normativas inspiradas en ideales consecuencialistas - con márgenes de flexibilidad o discrecionalidad aplicativa- su rendimiento puede no ser el óptimo en manos de agentes que, por formación y función, pueden carecer de la visión de sistema, de las herramientas y de la experiencia de que puede en cambio gozar una autoridad de sector ${ }^{51}$. La judicialización podrá en ocasiones dar buenos resultados (pues lo que se pierde en falta de visión de sistema y especialización parece ganarse en imparcialidad), pero estimo que -en los grandes números- ella conduce a la aleatoriedad; es decir, a la pérdida de predictibilidad, una variable tan importante para el agente que se desempeña en el campo productivo-económico ${ }^{52}$. En suma: los

a quien se dispone a intervenir en actividades altamente reguladas. Al respecto cfr. Roxin, C. Derecho Penal, op. cit, pp. 884 ss., especialmente p. 886 (\$21, nm 55).

${ }^{50} \mathrm{Si}$ no se tratase de un hallazgo posterior, podría pensarse que se está parafraseando la prevención Colombo-Vodanovic-Correa (considerando $2^{\circ}$ ), en STC Rol No 480: “debe distinguirse entre el conocimiento de las normas regulatorias que puede presumirse de un sujeto obligado cualquiera, que aquel que puede suponerse de una empresa que participa de un mercado densamente regulado. La discrecionalidad administrativa puede ser igualmente reprochable en ambas situaciones, pero el grado en que la ley puede delegar en la potestad reglamentaria no es igual. Y no lo es porque es razonable considerar que una empresa concesionaria conoce sus deberes reglamentarios más de lo que está llamado a conocer un ciudadano común”. La tesis de la certeza subjetiva criticada por Weezel, Alex Van, op. cit. p. 5 ss., parece aquí latir con fuerza.

51 Aunque debo aclarar que este razonamiento supone en dicha esfera un diseño institucional y una modalidad procedimental compatibles con el estándar de debido proceso, condiciones que, lamentablemente, no pueden considerarse descontadas en nuestro medio.

${ }^{52}$ Salvo que se dé con un modelo de judicialización que tienda a una alta especialización, con apoyo interdisciplinario. Cabría en todo caso preguntarse si tiene sentido que la regulación se construya desde el caso concreto, por jueces (aún si los más ilustrados). 
jueces parecen comportarse como adecuados aplicadores de reglas estrictas, en espacios de relativa comodidad hermenéutica (por formación y tradición). Su rendimiento puede en cambio verse mermado allí donde se trate de estándares, operativos en sectores complejos, dinámicos y tendencialmente lejanos a su quehacer habitual ${ }^{53}$.

\section{BIBLIOGRAFÍA}

AlCAlde, Enrique, "Bienes jurídicos protegidos y potestad sancionadora de la Administración", en AA.VV., Sanciones administrativas y derechos fundamentales: regulación y nuevo intervencionismo. Conferencias Santo Tomás de Aquino, Andros, Santiago, 2005, pp. 63-71.

AlCALDE, Enrique, "Aplicación de los principios de tipicidad, culpabilidad y proporcionalidad en la infracción administrativa”, en Actualidad Jurídica, No 24, 2011, pp. 69-84.

AlCAlde, Enrique, La responsabilidad de los directores de sociedades anónimas. Responsabilidad civil y penal administrativa, Ediciones Universidad Católica de Chile, Santiago, 2013.

Aguerrea, Pedro, "El estatuto constitucional de las penas. Su aplicación a las sanciones administrativas conforme a los antecedentes de la Comisión de Estudio de la Nueva Constitución", en AA.VV., Sanciones administrativas y derechos fundamentales: regulación y nuevo intervencionismo. Conferencias Santo Tomás de Aquino, Andros, Santiago, 2005, pp. 51-62.

Becker, Gary S., "Crime and Punishment: An Economic Approach", en The Journal of Political Economy, vol. 76, n. 2, 1968, pp. 169-217.

Becker, Gary S., "Nobel Lecture: The Economic Way of Looking at Behavior", en The Journal of Political Economy, vol. 101, n. 3, 1993, pp. 385-409.

Bernardi, Alessandro, "Nessuna pena senza legge", en Bartole, E, Conforti, B. y Raimondi, G. (Dir.), Commentario alla Convenzione Europea per la tutela dei diritto dell'nomo e delle libertà fondamentali, CEDAM, Padova, 2001, pp. 249-306.

Boettiger, Camila, "El derecho administrativo sancionador en la jurisprudencia del Tribunal Constitucional", en Actualidad Jurídica, No 20, 2009, pp. 577ss.

Buber, Martin, "Religión y Ética”, en ID., Eclipse de Dios, Ed. Nueva Visión, Buenos Aires, 1970. Bustos Ramírez, Juan, Manual de Derecho Penal. Parte General, Ed. Ariel, Barcelona, $3^{a}$ ed., 1989.

Calabresi, Guido, The Costs of Accidents. A Legal and Economic Analysis, Yale University Press, New Haven, 1970.

CAlabresi, Guido, "Remarks: The simple virtues of the Cathedral", en Yale Law Journal, vol. 106, 1996-1997, pp. 2201-2207.

Cooter, Robert, "Prices and Sanctions", en Columbia Law Review, vol. 84, 1984, pp. 1523-1560.

Cooter, Robert \& Ulen, Thomas, Law and Economics, Addison Wesley-Longman, 3a ed., 2000.

Cordero Q., Eduardo y Aldunate L., Eduardo, "Las bases constitucionales de la potestad sancionadora de la Administración", en Revista de Derecho de la Pontificia Universidad Católica de Valparaíso XXXIX, 2012 (2do Semestre), pp. 337-361.

Cordero Q., Eduardo, "El Derecho administrativo sancionador y su relación con el Derecho Penal”, en Revista de Derecho (Univ. Austral), 2012, vol. XXV, No 2, pp. 131-157.

${ }^{3}$ Cfr. Komesar, Neil K., Law's Limits. The rule of law and the supply and demand of rights, Cambridge University Press, New York, 2001, sp. pp. 5, 19 y 158, sosteniendo que el incremento cuantitativo y cualitativo (numbers \& complexity) de la demanda por derechos tendría un impacto negativo en el rendimiento de su oferta por los tribunales, ya debilitando o tornando ambiguas las respuestas, ya -incluso-aplazándolas en aras de una respuesta desde el nivel político. 
Cordero Vega, Luis, "En qué estamos con el Derecho Administrativo Sancionador", en El Mercurio Legal, 16 de agosto de 2011.

Cury Urzúa, Enrique, Derecho Penal. Parte General, Ediciones Universidad Católica de Chile, $7^{\text {a }}$ Ed., 2005.

Easterbrook, Frank H. \& Fischel, Daniel R., The Economic Structure of Corporate Law, Harvard University Press, Cambridge (MA, EE.UU.), 1991.

Finnis, John, Moral Absolutes: Tradition, Revision and Truth, Washington, 1991.

Grisez, Germain “Against Consequentialism”, en American Journal of Jurisprudence, vol. 23, 1978, pp. 21 ss.

Hart, Herbert L.A., The concept of law, Oxford University Press, $2^{\mathrm{a}}$ ed., 1994.

Hassemer, Winfried y Muñoz Conde, Francisco, Introducción a la Criminología y al Derecho penal, Tirant lo Blanch, Valencia, 1989.

Hernández Basualto, Héctor, Comentario al artículo 20 del Código Penal, en Couso, Jaime y Hernández, Héctor (Dir.), Código Penal Comentado. Parte General. Doctrina y Jurisprudencia, Ed. Abeledo Perrot-Legal Publishing, Santiago, 2011.

KAPLOW, Louis, "Rules versus standards: an economic analysis", en Duke Law Journal, vol. 42, 1992-1993, pp. 557-629.

Komesar, Neil K., Law's Limits. The rule of law and the supply and demand of rights, Cambridge University Press, New York, 2001.

LEwIs, Clive S., "The Humanitarian Theory of Punishment", en ID., God in the Dock: Essays on Theology and Ethics, Eerdmans Publishing, 1970, pp. 287 ss.

MacIntyre, Alasdair, Review, en Ethics, vol. 103, N. 4, Jul, 1993, pp. 811-812.

Mengoni, Luigi, Ermeneutica e dogmatica giuridica, Ed. Giuffrè, Milán, 1996.

Pedrazzi, Cesare, "Diritto Penale", en Diritto Penale, Scritti di Parte Generale, t. I. Giuffré, Milán, 2003.

RoDríGuez Collado, Luis, "Bases para distinguir entre infracciones criminales y administrativas", Revista de Derecho (PUCV), 1987, XI, pp. 117-163.

Roxin, Claus, "Sentido y límites de la pena estatal”, en Problemas Básicos del Derecho Penal (Trad. Diego M. Luzón Peña), Ed. Reus, Madrid, 1976.

Roxin, Claus, Derecho Penal. Parte General. Tomo I (trad. 2da ed. alemana), Ed. Civitas, Madrid, 1997.

Schmidt-Assmann, Eberhard, La teoría general del derecho administrativo como sistema, Marcial Pons, Madrid, 2003.

Silva Sánchez, Jesús María, Política Criminal y Persona, Ed. Ad hoc, Buenos Aires, 2000.

Silva Sánchez, Jesús María, La expansión del derecho penal. Aspectos de política criminal en las sociedades postindustriales, Civitas, 2da. Ed., Madrid, 2001.

Sото Kloss, Eduardo, "La potestad sancionadora de la Administración, ¿se adecua a la Constitución?”, en AA.VV., Sanciones administrativas y derechos fundamentales: regulación y nuevo intervencionismo. Conferencias Santo Tomás de Aquino, Andros, Santiago, 2005, pp. 29-49.

Spaemann, Robert, Felicità e benevolenza (Trad. Matteo Amori del original Glück und Woblwollen: Versuch über Ethik, Ed. Ernst Klett, 1989), Ed. Vita e Pensiero, Milán, 1998.

Spaemann, Robert, Concetti morali fondamentali (Trad. Luca F. Tuninetti del original Moralische Grundbegriffe, Ed. Beck, 1986), Ed. Piemme, Casale Monferrato, 2001.

Tiedemann, Klaus, Manual de Derecho Penal Económico, Tirant lo Blanch, Valencia, 2010.

Treschsel, Stefan, Human Rights in Criminal Proceedings, Oxford University Press, 2005, pp. 16-18.

Veas, Constanza, "Principio de Tipicidad en el Derecho Administrativo Sancionatorio", en Henríquez, Ian (Coord.), Derecho corporativo. Jurisprudencia Comentada. Año 2013, Legal Publishing -Thomson Reuters, Santiago, 2013, pp. 77-82.

Weezel, Alex Van, La Garantía de Tipicidad en las Jurisprudencial del Tribunal Constitucional, Abeledo Perrot - Thomson Reuters, Santiago, 2011. 
